\title{
Araucaria araucana im Palmengarten - erstmals mit weiblichen Zapfen
}

\author{
Roland Rudolph \& Hilke Steinecke
}

\section{Abstract}

Monkey puzzle trees grow very slowly and rarely produce cones. In summer 2007, the first mature seeds of about 50 years old Monkey puzzle trees in the Palmengarten could become ripe.

\section{Zusammenfassung}

Chilenische Araukarien (Araucaria araucana) wachsen bei uns sehr langsam und setzen eher selten Zapfen an. Im vergangenen Sommer konnten im Palmengarten erstmals an etwa 50 Jahre alten Araukarien die Samen voll ausreifen.

\section{Verbreitung der Araukarien}

Die Gattung Araucaria umfasst 18 Arten, die ihre natürliche Heimat auf der Südhalbkugel haben (Pazifischer Raum, davon 13 Arten in Neukaledonien sowie zwei Arten in Südamerika). Araucaria araucana (Chilenische Araukarie, Andentanne, Pinonero, Monkey puzzle tree) ist eine der eindrucksvollsten Koniferen der Südhalbkugel, die auch bei uns winterhart ist, allerdings nur sehr langsam wächst. Sie stammt aus dem südlichen Mittel-Chile und dem angrenzenden Argentinien, hat ihre Heimat in den Anden sowie in der Küstenregion. Nur in den unzugänglichen Teilen der heutigen Nationalparks, hauptsächlich an den Hängen der schneebedeckten Vulkane, haben Reste der ehemals riesigen Wälder überlebt. Ihr Vorkommen beschränkt sich auf die Höhenlagen von ca. $1000 \mathrm{~m}$ bis an die Baumgrenze in über $2000 \mathrm{~m}$ Höhe. Es sind majestätische Bäume, die einem wie Relikte einer längst vergangenen Epoche im Gedächtnis bleiben. Araukarienwälder sind streng geschützt. Im Palmengarten sind mehrere Exemplare, mittlerweile etwa sechs Meter hoch, im Sommer-Sukkulentengarten zu bewundern.

\section{2. Äußeres Erscheinungsbild}

Araukarien haben einen charakteristischen steifen Wuchs mit ausgeprägten Astquirlen. Eine ähnliche Wuchsform zeigen ja auch die beliebten Zimmertannen (Araucaria heterophylla), enge Verwandte der Andentanne. Jüngere Araukarien, wie die Exemplare im Palmengarten, tragen auch an der Stammbasis Äste, ältere werfen die unteren Äste ab und bilden eine schirmförmige Krone, die sich aus Quirlen mit 3-7 regelmäßig angeordneten, waagerecht vom Stamm abstehenden oder leicht aufwärts gerichteten Ästen aufbaut. Um diese Wuchsform zu sehen, muss man nicht auf die Südhalbkugel reisen. Im atlantischen West-Europa sowie in Großbritannien, und dort besonders im milden Cornwall, werden Araukarien seit über 100 Jahren gepflanzt. Dementsprechend sind die Kronen älterer Bäume charakteristisch schirmförmig aufgebaut.

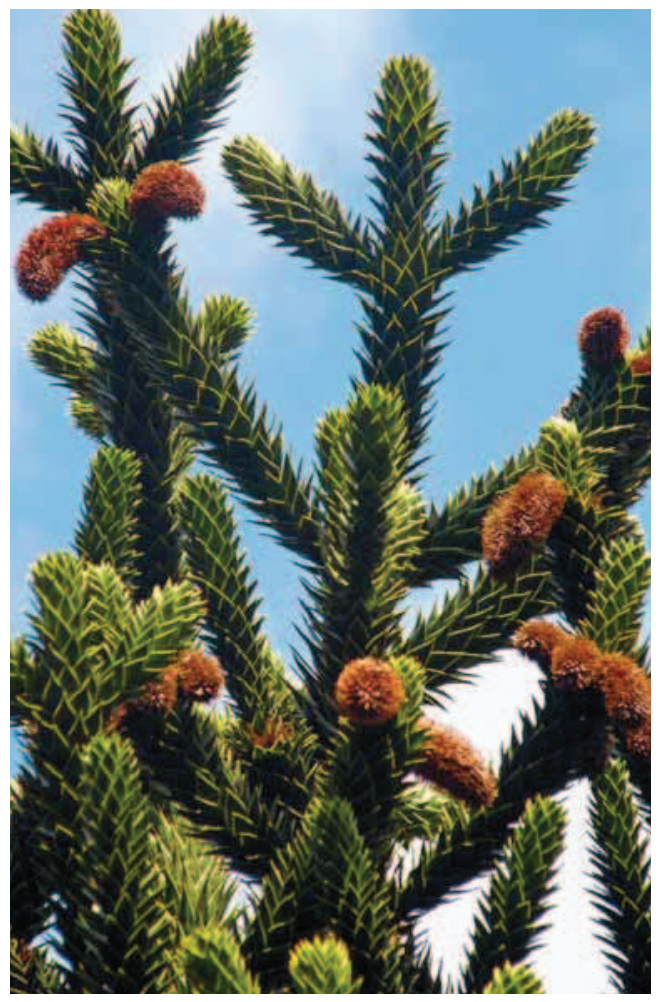



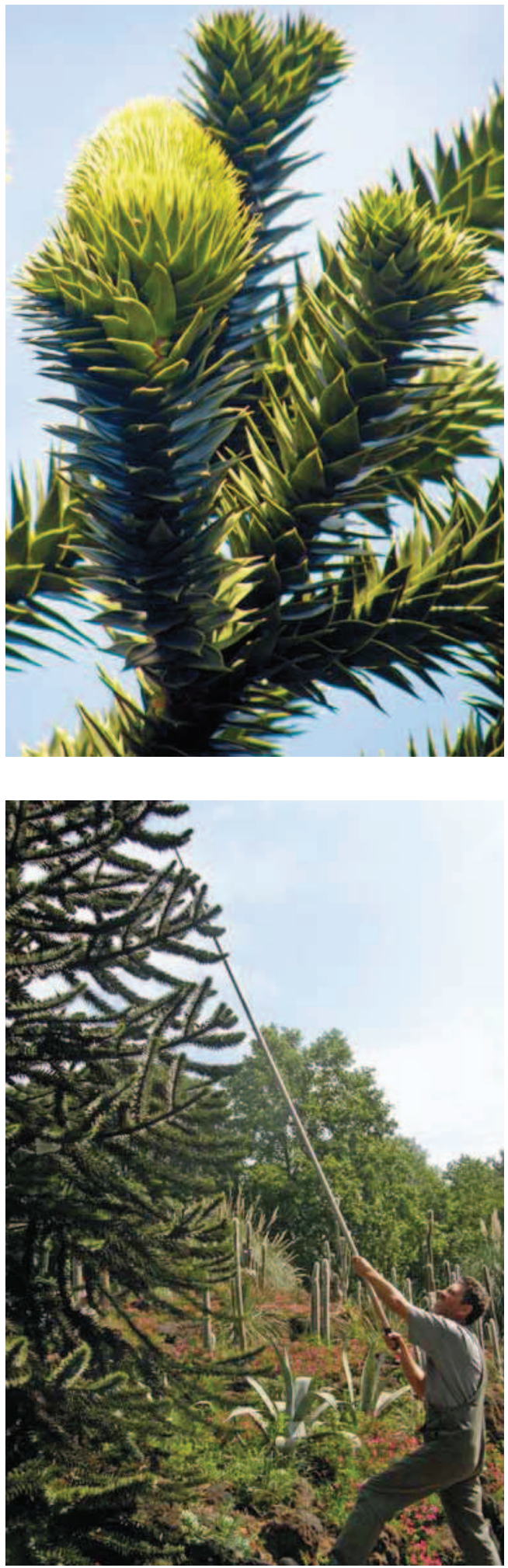

Araukarien mit derartiger Wuchsform sind dagegen in Deutschland nur sehr selten anzutreffen, da die Bäume in unserem Klima nur sehr langsam wachsen und in Gebieten mit relativ strengen Wintern nur bedingt freilandtauglich sind. Die Äste sind relativ biegsam und verhindern dadurch Schneedruckschäden. Die breitdreieckigen Nadeln sind sehr spitz und stechend. Der englische Name Monkey puzzle tree bezieht sich vermutlich auf diese unangenehme Benadelung. Diesen Namen verdankt die Araukarie vermutlich einem Besucher der Gärten in Pancarrow in Cornwall im 19. Jahrhundert, als er das erste Mal eine junge Araukarie sah. Er vermutete, dass die spitzen Nadeln jedem Affen Kopfzerbrechen bereiten würden, der versuchen wollte, in den Baum zu klettern (engl. monkey $=$ Affe und to puzzle $=$ Kopfzerbrechen bereiten). Dabei hatte er nicht bedacht, dass es in Chile gar keine Affen gibt, das Problem sich also gar nicht stellt (vgl. MusGrave et al. 1998).

Araukarien sollen ein Höchstalter von etwa 1000 Jahren erreichen. Die Araukarien im Palmengarten wurden Ende der 1980er Jahre im Alter von ca. 30 Jahren gepflanzt. Seit dieser Zeit sind sie um etwa zwei Meter gewachsen. Da die Stämme ziemlich gerade wachsen, liefern Araukarien ein hochwertiges Holz. Die Spanier, die im 16. Jh. Südamerika eroberten, nutzten die bis 30 Meter hohen und kerzengerade gewachsenen Stämme zum Bau ihrer Schiffe und für die Herstellung von Masten. In Brasilien werden aus dem Holz von Araucaria angustifolia kunsthandwerkliche Gegenstände angefertigt. Beliebt sind Teller, die aus dem Holz im Bereich eines Astquirls hergestellt wurden. Das Holz der Seitenäste erscheint dunkler und ergibt auf dem Teller ein kontrastreiches Muster.

Abb. 2 (oben): Weiblicher Zapfen.

Abb. 3 (unten): Samenernte.

Abb. 4 (Seite 23, oben links): Reife Araukariensamen.

Abb. 5 (Seite 23, oben rechts): Fossiler Araukarienzapfen.

Abb. 6 (Seite 23, unten): Araukarien am Standort in Chile. 

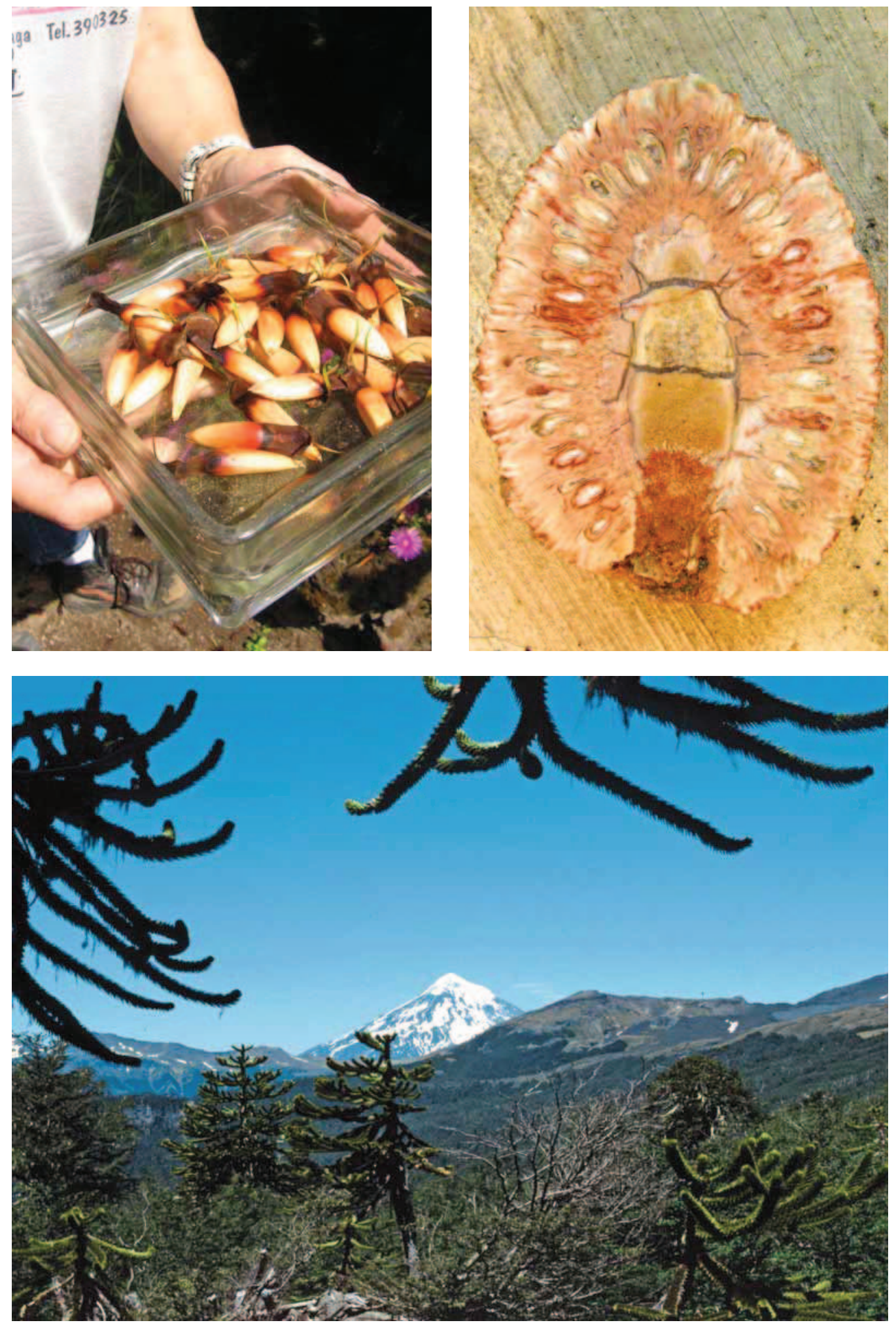


\section{Zapfen und Samen}

Araukarien sind zweihäusig, d. h. es gibt männliche und weibliche Bäume. An den Zweigspitzen entwickeln sich entweder dünne männliche Zapfen, die bei der Reife massenhaft Pollen ausstreuen, so dass es aussieht, als ob der Baum „rauchen“ würde, oder rundliche weibliche Zapfen. Diese werden bis $20 \mathrm{~cm}$ dick und sie benötigen von der Befruchtung bis zur Reife 18 Monate. Sie zerfallen dann ähnlich wie die Zapfen der Tanne und entlassen 120-200 längliche, abgeflachte Samen. Am Baum bleibt nur die Spindel des Zapfens zurück. Die so genannten piñones sind essbar und sehr nahrhaft. In Südamerika bekommt man sie in gerösteter Form, ähnlich wie bei uns Kastanien, auf den lokalen Märkten zu kaufen (vgl. KRÜssmanN 1983).

Im Sommer-Sukkulentengarten stehen sowohl männliche als auch weibliche Exemplare, die seit wenigen Jahren Zapfen bilden. Die weiblichen fallen durch ihre rundliche Form

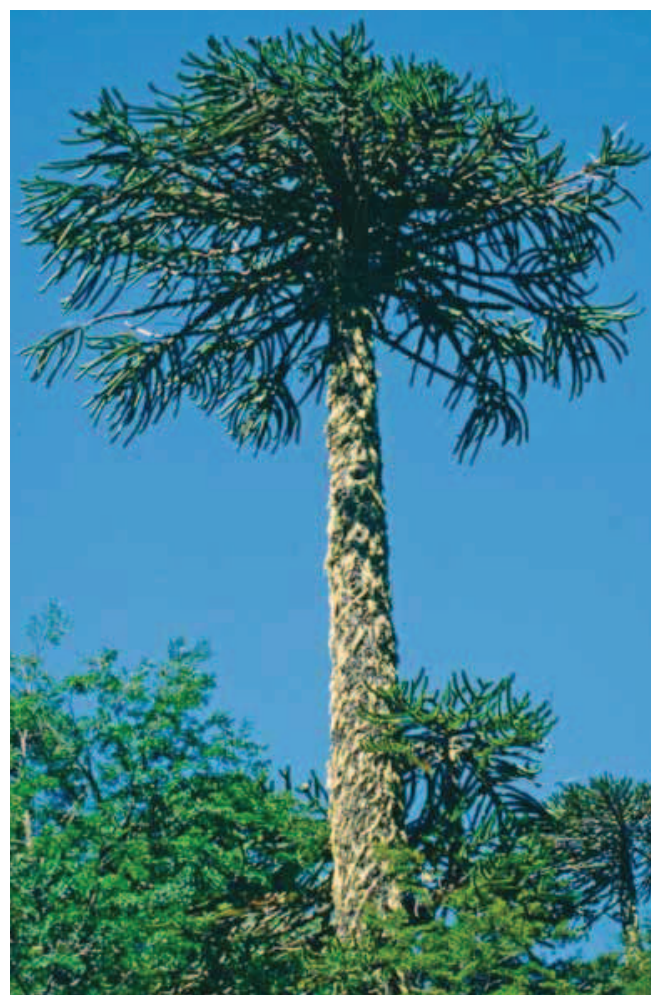

und grüne Farbe auf. Der heiße und trockene Sommer 2006 sowie der darauf folgende milde Winter mögen dazu beigetragen haben, dass sich die Samen mehrerer Zapfen erstmals bis zur Reife entwickeln konnten. Ein Teil der Samen wurde ausgesät, wir sind gespannt auf den eigenen Araukarien-Nachwuchs.

In die Familie der Araukariengewächse wird außer Agathis (Kaurifichte) auch die berühmte Wollemia nobilis gestellt, ein erst 1994 in Australien entdecktes lebendes Fossil, das im Nebelwaldhaus des Tropicarium zu betrachten ist.

Aus der Jura-Zeit (vor ca. 190 Mio. Jahren) sind versteinerte Araukarien-Zapfen erhalten. Der versteinerte Wald von Cerro Cuadrado in Patagonien zählt zu den schönsten Fundstellen von versteinertem Holz. Ganz besonders begehrt sind die versteinerten Araukarien-Zapfen, die von der Qualität ihrer Versteinerung einmalig sind. Sämtliche Feinstrukturen der Zapfen haben sich über Jahrmillionen hinweg erhalten. In längs halbierten, polierten Zapfen sind teilweise sogar noch die Embryonen in den Samen zu erkennen. Gelegentlich werden kleinere versteinerte Araukarienzapfen als Schmuck angeboten.

\section{Literatur}

Krüssmann, G. I983: Handbuch der Nadelgehölze. Berlin.

Musgrave, T., Gardner, C. \& Musgrave, W. 1998: Pflanzensammler und -entdecker. - München. 